\title{
Effect of Nanopowder Addition on the Sintering of Water-Atomized Iron Powder
}

\author{
SWATHI K. MANCHILI, JOHAN WENDEL, ABDELHAFID ZEHRI, JOHAN LIU, \\ EDUARD HRYHA, and LARS NYBORG
}

\begin{abstract}
A promising method of improving the densification of powder metallurgical steel components is to blend nanopowder with the otherwise typically used micrometre-sized powder. The higher surface-to-volume ratio of nanopowder is hypothesized to accelerate the sintering process and increase the inter-particle contact area between the powder particles. This is supposed to enhance the material transport and improve the densification. In the present investigation, water-atomized iron powder $(-45 \mu \mathrm{m})$ was mixed separately with pure iron and low-carbon steel nanopowder, each at a ratio of 95 to 5 pct. These powder mixes were compacted at different pressures $(400,600$ and $800 \mathrm{MPa})$ and then sintered at $1350{ }^{\circ} \mathrm{C}$ in a pure hydrogen atmosphere. The sintering behavior of the powder blend compacts was compared to that of the compact with micrometre-sized powder only. Densification commenced at much lower temperatures in the presence of nanopowder. To understand this, sintering at intermittent temperatures such as 500 ${ }^{\circ} \mathrm{C}$ and $700{ }^{\circ} \mathrm{C}$ was conducted. The fracture surface revealed that the nanopowder was sintered at between $500{ }^{\circ} \mathrm{C}$ and $700{ }^{\circ} \mathrm{C}$, which in turn contributed to the densification of the powder mix at the lower temperature range. Based on the sintering experiments, an attempt was made to calculate the activation energy and identify the associated sinter mechanism using two different approaches. It was shown that the first approach yielded values in agreement with the grain-boundary diffusion mechanism. As the nanopowder content increased, there was an increase in linear shrinkage during sintering.
\end{abstract}

https://doi.org/10.1007/s11661-020-05891-1

(C) The Author(s) 2020

\section{INTRODUCTION}

THE press and sinter route offers cost-effective solutions in the manufacturing of powder metallurgical (PM) steel components for structural applications. There is a constant drive to improve the density of PM steel, which expands its usage in applications demanding higher performance than what it currently delivers. Sintering is an important step in the PM manufacturing route and involves the transfer of powder compact into a high-density body that minimizes residual porosity while controlling tolerances. The process of so-called solid-state sinter occurs at temperatures below the melting point of the particles, and the properties of the product are a direct function of the sinter neck development and the degree of

SWATHI K. MANCHILI, JOHAN WENDEL, EDUARD HRYHA, and LARS NYBORG are with the Department of Industrial and Materials Science, Chalmers University of Technology, 41258 Gothenburg, Sweden. Contact e-mail: manchili@chalmers.se ABDELHAFID ZEHRI and JOHAN LIU are with the Department of Microtechnology and Nanoscience, Chalmers University of Technology, 41258 Gothenburg, Sweden.

Manuscript submitted January 16, 2020.

Article published online July 1, 2020 densification. ${ }^{[1]}$ Understanding sintering is therefore important, because the performance of the component largely depends on this process. For densification to occur, material flow is required. This largely depends on the sintering temperature and particle size. Surface diffusion mechanisms for material flow facilitate neck formation between the metal particles, whereas bulk diffusion mechanisms are required for the densification of the component. ${ }^{[2]}$ Densification is accomplished by increasing the temperature of the powder compact to enable material transport. The metal particles change their morphology to reduce the total energy of the system. This has been explained at both a coarse and fine scale. Necks are formed between the particles, comprising metallurgical bonds in nature, and they gradually approach one another, which in turn leads to shrinkage and densification. Mass transport mechanisms describe sintering on a fine scale. Sintering not only results in the densification of the compact but also leads to grain growth because the process is followed within the grain growth temperature range. Grain growth or coarsening occurs during the final stage of sintering as the temperature is sufficient to drive the coarsening process. ${ }^{[3]}$ A promising method of improving densification is the use of bimodal mixes. A high 
surface-to-volume ratio enhances the reactivity of the nanoparticles. Because the large surface area enhances the surface energy, nanopowder is considered to have lower activation energy for sintering. ${ }^{[4,5]}$ However, with this advantage, there is also the problem of strong agglomeration accompanying the high surface energy and the problem of increase in inter-particle friction. ${ }^{[, 7]}$ Tapping the full potential of these nanostructured materials across the spectrum of applications requires a simple and cost-effective method of producing and processing them in bulk form. However, oxidation and high cost make nanopowder difficult to use for bulk PM applications. To overcome the disadvantages of nanopowder, it can be used in combination with micrometre-sized powder and simultaneously as an aid in the sintering of the micrometre-sized powder compacts. The combination of nanopowder and micrometre-sized powder has been explored by researchers in the field of metal injection molding (MIM) ${ }^{[8]}$ It has been found that a compact of nanopowder with micrometre-sized powder micro-nanopowder compact possesses a much higher strength after sintering at $500{ }^{\circ} \mathrm{C}$ compared to the compact made from micrometre-sized powder. ${ }^{[8]}$

The objective of the current study is to investigate the influence of nanopowder addition on the sintering of micrometre-sized iron-based powder compacts using the conventional powder-metallurgy method of pressing and sintering. This paper studies uniaxial compaction and sintering behaviour, as well as the microstructural evolution during sintering. Powder blends were created by mixing $95 \mathrm{wt}$ pct micrometre-sized iron powder with 5 wt pet nanopowder. Two types of nanopowder were used: pure iron nanopowder and low-alloy steel (LAS) nanopowder. Micrometre-sized powder was mixed with the nanopowder, and the mixture was processed using various compaction pressures and subsequently subjected to sintering.

\section{MATERIALS AND METHODS}

\section{A. Materials and Mixing}

For the nanopowder, pure iron nanopowder with an average particle size of $50 \mathrm{~nm}$ was procured from Sigma-Aldrich Inc. Steel nanopowder was produced using an in-house nanopowder fabrication technology. For the steel nanopowder, LAS (Fe-1.3 pct Mn-0.2 pct Si-0.24 pet C-0.06 pet P-0.06 pct S) was used as the starting material. A micrometre-sized powder of pure iron with a $D_{50}$ of $30 \mu \mathrm{m}$ was supplied by Höganäs AB. The micrometre-sized powder and nanopowder were mixed at a ratio of 95 to $5 \mathrm{wt}$ pct. Preliminary mixing was conducted in a tumbler placed in a glovebox for 12 hours. This yielded two types of powder blends: micro-5 pct iron nanopowder (M-5 pct Fe) and micro-5 pct steel nanopowder (M-5 pct LAS). Further, carbon in the form of natural graphite, UF-4, was added to prepare more blends. This yielded in blends designated as M-5 pctFe +0.4 pctC $(\mathrm{M}-5$ pct $\mathrm{Fe}+\mathrm{C})$ and M-5 pctLAS + 0.4 pctC $(\mathrm{M}-5$ pct LAS $+\mathrm{C})$. There were thus four different powder blends in total.

More powder mixes were made to study the influence of various amounts of nanopowder in the compact. For this purpose, iron nanopowder was mixed with micrometre-sized powder at different weight fractions, namely 10,15 and $20 \mathrm{wt}$ pet.

\section{B. Compaction and Sintering}

The powder blends were compacted using a compaction press under uniaxial loading conditions. Prior to compaction, $0.6 \mathrm{wt}$ pct lubricant (Lube-E) was added to the blends to improve the compressibility of the powder and to improve die life by reducing die wall friction during compaction. Compaction pressures of 400, 600 and $800 \mathrm{MPa}$ were employed. Cylindrical samples with height 13.5 to $14.5 \mathrm{~mm}$ and diameter $11.5 \mathrm{~mm}$ were thus prepared from the powder blends.

Before sintering began, the compacts were subjected to delubrication in the presence of argon gas. The compacts were heated to $450{ }^{\circ} \mathrm{C}$ at a heating rate of $10{ }^{\circ} \mathrm{C} / \mathrm{min}$ and held isothermally at $450{ }^{\circ} \mathrm{C}$ for 30 minutes. The temperature of delubrication was chosen after runs using thermogravimetry in argon gas. This step is essential to ensuring that no contaminants enter the dilatometer and to the efficient densification of the compact. Details on the sintering experiments are given in Table I. Delubricated compacts were sintered at $1350{ }^{\circ} \mathrm{C}$ using a DIL $402 \mathrm{C}$ horizontal push rod dilatometer (NETZSCH Thermal Analysis GmbH, Germany) (DIL). Sintering was conducted under 99.9999 pct pure hydrogen gas. Green compacts were heated to $1350{ }^{\circ} \mathrm{C}$ for sintering using different heating rates $\left(5^{\circ} \mathrm{C} / \mathrm{min}, 10{ }^{\circ} \mathrm{C} / \mathrm{min}, 15^{\circ} \mathrm{C} / \mathrm{min}, 25^{\circ} \mathrm{C} / \mathrm{min}\right.$ and $30{ }^{\circ} \mathrm{C} / \mathrm{min}$ ), held there isothermally for 30 minutes and then cooled to room temperature at a cooling rate of $30{ }^{\circ} \mathrm{C} / \mathrm{min}$. The temperature of $1350{ }^{\circ} \mathrm{C}$ is well above what is used in industrial-scale sintering of PM steel and was chosen to study the entire range of sintering. Three samples were sintered for every condition.

Some of the green compacts were also sintered at intermittent temperatures of $500{ }^{\circ} \mathrm{C}, 700{ }^{\circ} \mathrm{C}, 900{ }^{\circ} \mathrm{C}$ and $1100{ }^{\circ} \mathrm{C}$ with a heating rate of $10{ }^{\circ} \mathrm{C} / \mathrm{min}$ and final isothermal holding of 30 minutes.

\section{Characterization}

The density of the green compacts was evaluated using a micrometre and a simple balance with an accuracy of $0.0001 \mathrm{~g}$. The micrometre was used to measure the height and diameter and calculate the volume of the compact. The simple balance was used to measure the mass of the sample. The density of the 
Table I. Details of the Sintering Experiments

\begin{tabular}{lccc}
\hline Powder Blend & Compaction Pressure $(\mathrm{MPa})$ & Sintering Temperature $\left({ }^{\circ} \mathrm{C}\right)$ & Atmosphere \\
\hline M-5 Pct Fe & $400,600,800$ & 1350 & hydrogen \\
M-5 Pct Fe + C & $400,600,800$ & 1350 & hydrogen \\
M-5 Pct LAS & $400,600,800$ & 1350 & hydrogen \\
M-5 Pct LAS + C & $400,600,800$ & 1350 & hydrogen \\
\hline
\end{tabular}

$L A S$ low-alloy steel.
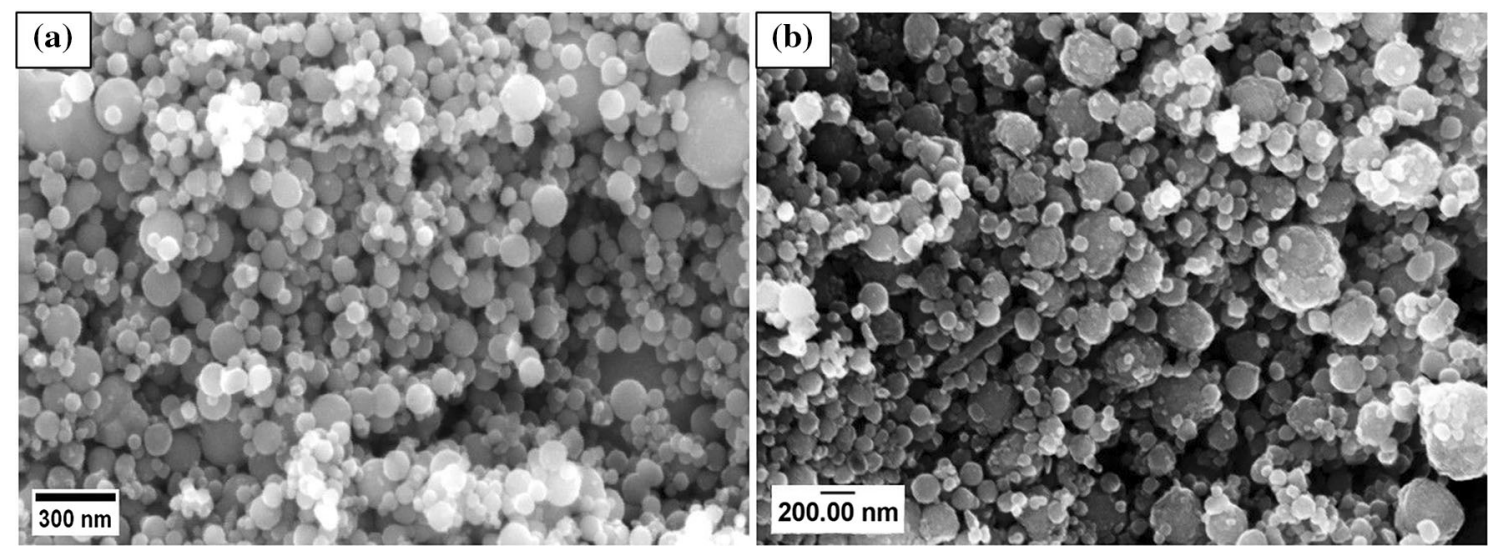

Fig. 1-Scanning electron micrograph of $(a)$ iron nanopowder and $(b)$ low-alloy steel nanopowder. A laser particle analyzer was used to measure the particle-size distribution of the micrometre-sized powder. The average size of the particles was found to be $30 \mu \mathrm{m}\left(D_{50}=30 \mu \mathrm{m}\right)$, with most of the particles being under $45 \mu \mathrm{m}$.

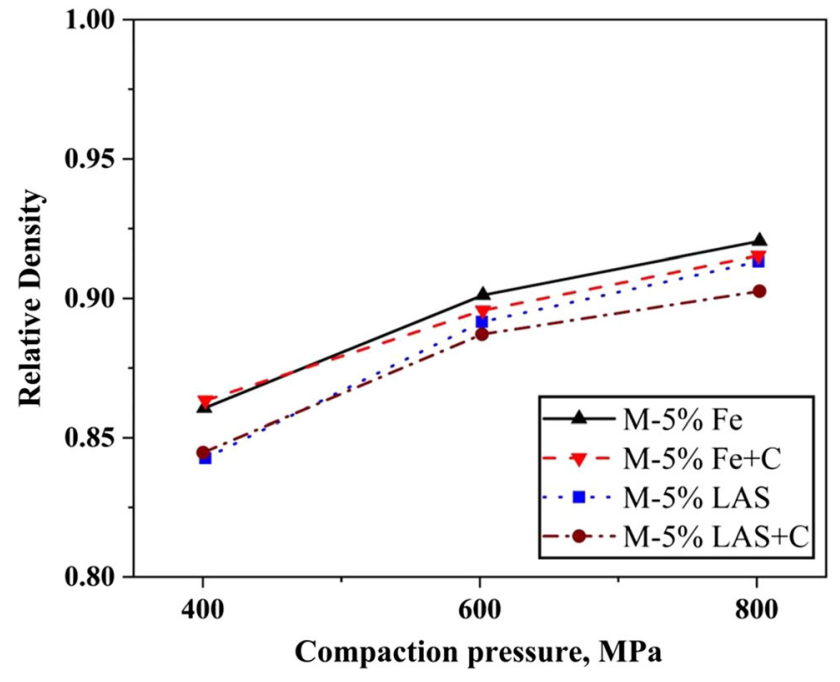

Fig. 2 - Compressibility curve for the powder blends.

sintered compact was also measured using the Archimedes principle according to measuring standard MPIF 42. Scanning electron microscopy (SEM) was performed using an electron microscope LEO Gemini 1550 (CARL ZEISS-LEO, GmbH equipped with a field emission gun: FEG-SEM) to evaluate the mixing of nanopowder with micrometre-sized powder. An In-lens secondary electron detector was used for this analysis. Fracture surfaces of compacts sintered at different temperatures were also evaluated using the FEG-SEM. Leitz DMRX from Leica was used to perform optical microscopy.

\section{RESULTS AND DISCUSSION}

\section{A. Materials and Compaction}

Iron nanopowder examined in this study was found to be spherical in shape with particle size less than $100 \mathrm{~nm}$ (Figure 1(a)). Steel nanopowder in this study was found to be agglomerated, and the size of the particles had a broad range, approximately $40 \mathrm{~nm}$ to micrometre (Figure 1(b)). The common problem associated with small particle size is agglomeration. This is also referred to as sintering during synthesis. Such agglomeration is detrimental to sintering because the size advantage could be compromised. The passive layer present on the iron nanopowder helped reduce the agglomeration to a certain extent. Because such a film did not develop on the LAS nanopowder, it was prone to agglomeration. A surface analysis of both the nanopowder and the reduction of surface oxide has been discussed elsewhere. ${ }^{[9]}$

The powder blends and the lubricant were compacted at compaction pressures of 400,600 and $800 \mathrm{MPa}$. Figure 2 shows the compressibility curves for the compacts of all the powder blends. Green density, being a direct function of compaction pressure, increases with increasing compaction pressure. The M-5 pct Fe blend showed high compressibility with a relative green 
density of approximately 0.92 (of the theoretical density) after compaction at $800 \mathrm{MPa}$. As for the M-5 pet Fe + $\mathrm{C}$ blend, the relative green density decreased due to the presence of graphite. The presence of graphite in M-5 pct LAS + C blend meant a decreased green density compared to the M-5 pct LAS blend. Though the density of these compacts was less compared to the M-5 pet Fe and M-5 pct Fe $+\mathrm{C}$ compacts. This could be attributed to the higher green strength of LAS compared to the pure iron which was present in the form of nanopowder in the compact. Dominguez et al. ${ }^{[10]}$ observed that compressibility decreased with increasing compaction pressure when nanopowder was present in powder blends. ${ }^{[10]}$ Moreover, the green density values of the compacts with the powder blends would be lower than the green density values of the compact with only micrometre-sized powder (without nanopowder). ${ }^{[11]}$

Because of the lower green density values of the powder blend compacts, the compressibility of the mixed powder decreased with increasing amounts of iron nanopowder in the mixture. Figure 3 shows the decreasing compressibility when the powder with varying amounts of nanopowder compacted at $600 \mathrm{MPa}$. The green compact with $5 \mathrm{wt}$ pct nanopowder had a relative density of approximately 0.91 , which decreased to 0.88 with $10 \mathrm{wt}$ pet nanopowder and then to 0.86 and 0.85 with 15 and 20 wt pet nanopowder, respectively. It can thus be said that the green density decreases with an increase in the weight fraction of nanopowder content. Dominguez et al..$^{[10]}$ studied how green density changes with the particle size of the powder and the behavior which influences the consolidation of ultrafine iron powder. They confirmed that in unidirectional compaction, iron nanopowder cannot attain high green density compared to conventional micrometric powder even when pressed at a high compaction pressure. This might be attributed to the increase in the compacted material's yield resistance with the decrease in the particle size. ${ }^{[10]}$

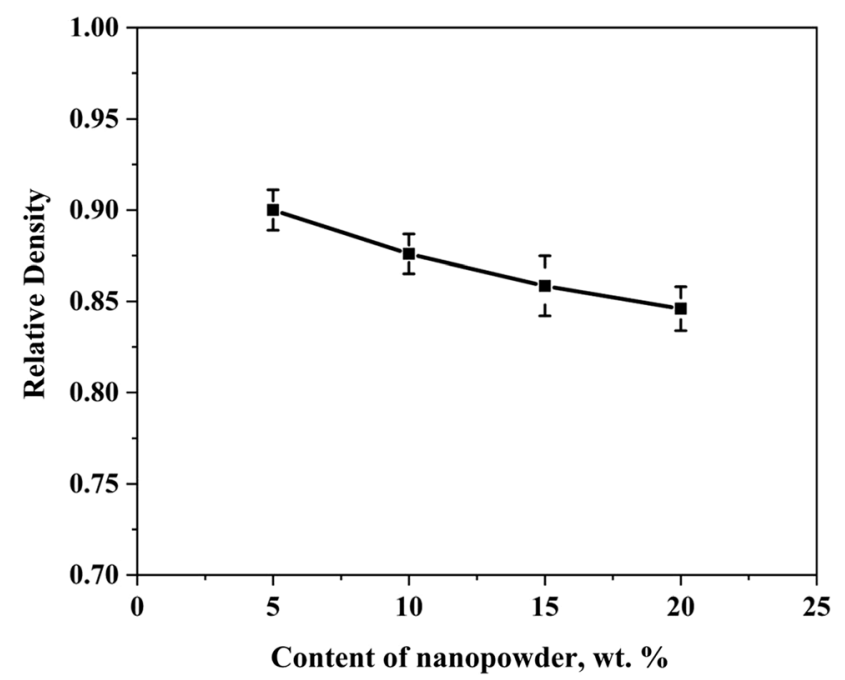

Fig. 3-Plot showing the effect of nanopowder on the compressibility of the M- $X$ pct Fe compact ( $X$ here is 5, 10, 15 and 20).

\section{B. Sintering}

Delubrication was conducted before sintering to dispose of the lubricant in the green compact.

The sintering curve was recorded using DIL, where the change in linear dimension of the specimen is measured as a function of time and temperature. Figure 4 shows sintering curves for the powder blends pressed at different compaction pressures and sintered with a heating rate of $10^{\circ} \mathrm{C} / \mathrm{min}$. All the compacts were sintered under identical conditions. During the heating stage of sintering, the material undergoes expansion, and the slope of the curve gives the coefficient of thermal expansion. In the present work, during the heating stage, this expansion phenomenon was countered by the densification due to the addition of nanopowder. This is explained in detail in Section III-C. During the isothermal hold, there was shrinkage in all cases. During the cooling stage, the compact was expected to shrink, and it did.

Increasing compaction pressure means that the shrinkage in the sintering curve increases. In the case of the M-5 pct Fe compacts, shrinkage increased from 1 to $1.5 \mathrm{pct}$ as the compaction pressure was increased from 400 to $800 \mathrm{MPa}$ (Figure 4(a)). A similar trend was observed in the compacts with carbon, where the shrinkage increased from 1.6 to 2.2 pct with increasing compaction pressure (Figure 4(b)). For the M-5 pct LAS compacts, the shrinkage was the same irrespective of the compaction pressure (Figure 4(c)), but for the M-5 pct LAS + C compacts, shrinkage was raised from 1.5 to 2.2 pct with increasing compaction pressure (Figure 4(d)). The shape of the sinter curve is also influenced by the presence of carbon (Figures 4(b) and (d)). This was mainly apparent for the temperature region after the phase transformation (alpha to gamma) and up to the isothermal holding temperature. There is no apparent explanation for the change in shape of sinter curve in this temperature range, but it could be related to the solubility of carbon in $\gamma$-Fe for the given temperature range.

The density of the sintered compacts was measured and plotted along with the densification parameter $(\Psi$; Figure 5). The densification parameter was also calculated for all the compacts, as the starting density was different for each compact, and this parameter serves as a tool to normalize the density values. The densification parameter was used to evaluate the ability of the compact to densify during sintering. This parameter was calculated using the following formula ${ }^{[12]}$ :

$$
\Psi=\frac{\rho_{\mathrm{s}}-\rho_{\mathrm{g}}}{\rho_{\mathrm{t}}-\rho_{\mathrm{g}}}
$$

where $\rho_{\mathrm{s}}$ is the sinter density, $\rho_{\mathrm{g}}$ is the green density and $\rho_{\mathrm{t}}$ is the theoretical density. This can also be defined as the fractional densification achieved with respect to the theoretically maximum attainable densification. ${ }^{[13]}$ The maximum relative sinter density of 0.93 was observed for the M-5 pct Fe and M-5 pct Fe + C compacts that had been compacted at $800 \mathrm{MPa}$. As previously mentioned, with an increase in compaction pressure from 400 to $800 \mathrm{MPa}$, there was also an increase in the 


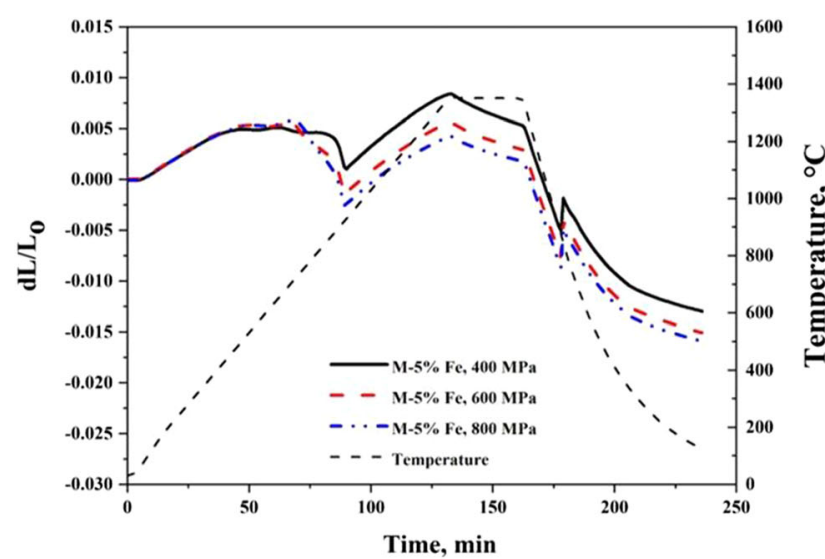

(a)

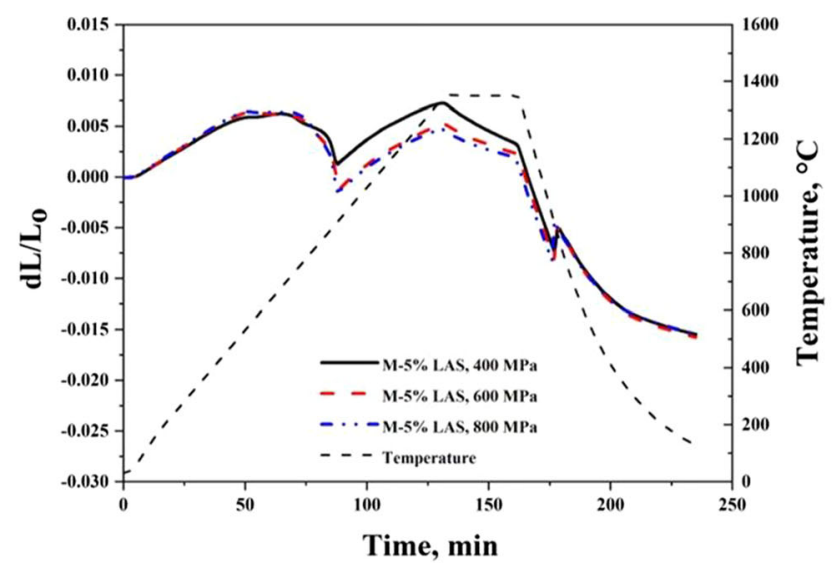

(c)

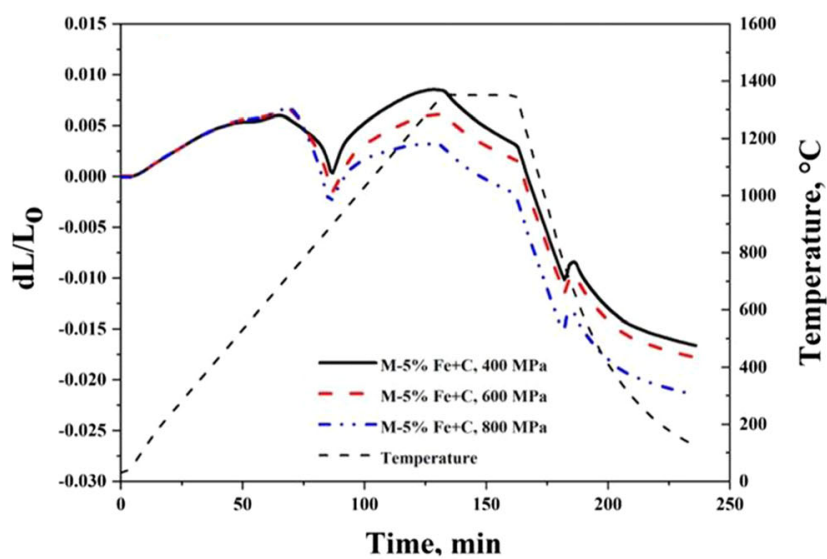

(b)

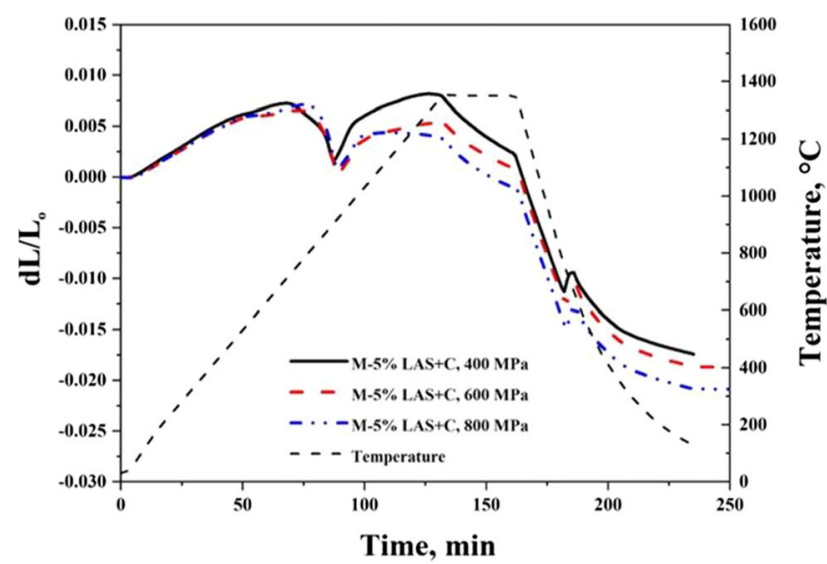

(d)

Fig. 4 - Sintering curves for (a) M-5 pctFe, (b) M-5 pctFe + C, (c) M-5 pctLAS and (d) M-5 pctLAS + C.

relative density of the compacts. Densification during powder compaction is connected to the particles' rearrangement in lower-pressure regions followed by plastic deformation of the particles at higher pressures. Figure 5 shows that the green density of the compacts for the same compaction pressure varies as the composition of the powder blend changes. The green density of the M-5 pet Fe compacts (Figure 5(a)) was high compared to other powder blend compacts. With an increase in green density, the amount of densification of the compact during sintering reduced. This in turn decreased the densification parameter. However, as shown in Figures 5(b) and (c), the densification parameter increased and then decreased with an increase in compaction pressure. Figure 5(d) shows that the densification parameter decreased with an increase in compaction pressure but then remained relatively the same upon a further increase in compaction pressure. Because the compacts were subjected to different compaction pressures, the green density between them varied, and consequently, so did the percentage of densification they underwent. The densification parameter defines the ability of a green compact to undergo densification when it is subjected to sintering. When the compaction pressure is low, densification is high, because there is a high amount of shrinkage. As the pressure is increased further, compaction-based densification dominates and hence results in a lower densification factor. Metallurgical bond formation is the only phenomenon which occurs during sintering with little or no shrinkage. In contrast, components molded by MIM, whose green density is quite low in comparison to press and sinter components, have a high densification parameter on sintering.

Three rates were employed to sinter the compacts: 5 , 10 and $30{ }^{\circ} \mathrm{C} / \mathrm{min}$. Figure 6 shows the heating section of the sintering curve for the M-5 pct Fe and M-5 pct Fe + $\mathrm{C}$ compacted at $600 \mathrm{MPa}$. The influence of the heating rate employed for sintering had only a minor influence on the shrinkage level. The effect of the heating rate on the allotropic transformation of iron was especially apparent. Figure 6 shows that with an increasing heating rate, the transformation temperature shifted to a higher value. The transformation temperature shifted from $925^{\circ} \mathrm{C}$ to $953{ }^{\circ} \mathrm{C}$ when the heating rate increased from $5{ }^{\circ} \mathrm{C} / \mathrm{min}$ to $30^{\circ} \mathrm{C} / \mathrm{min}$ for the $\mathrm{M}-5$ pct Fe sintered compacts (Figure 6(a)). ${ }^{[14]}$ The shift in the transformation was large in the case of M-5 pct $\mathrm{Fe}+\mathrm{C}$ : The 


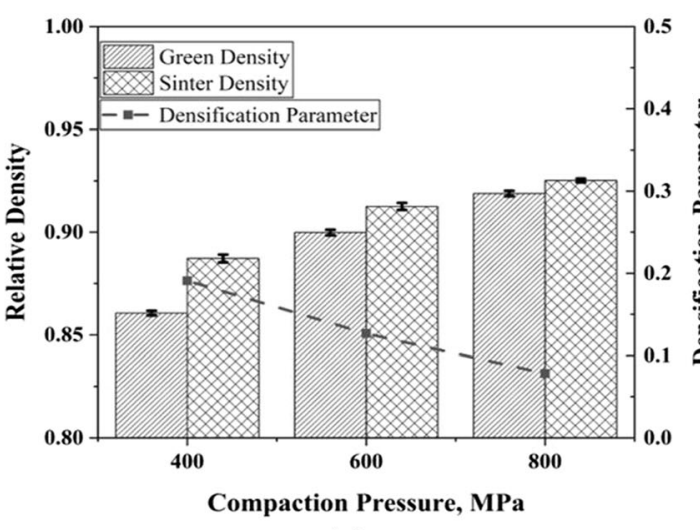

(a)

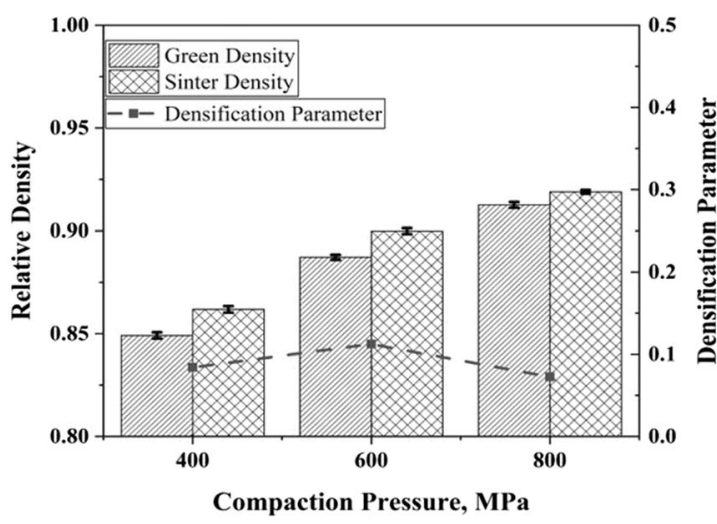

(c)

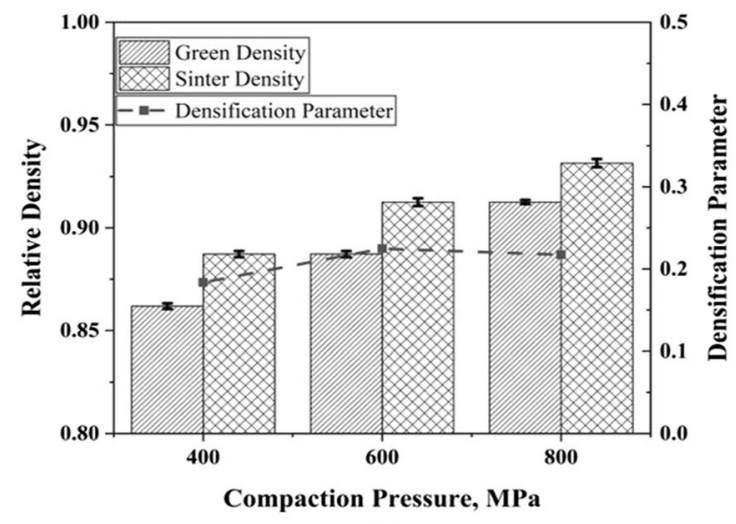

(b)

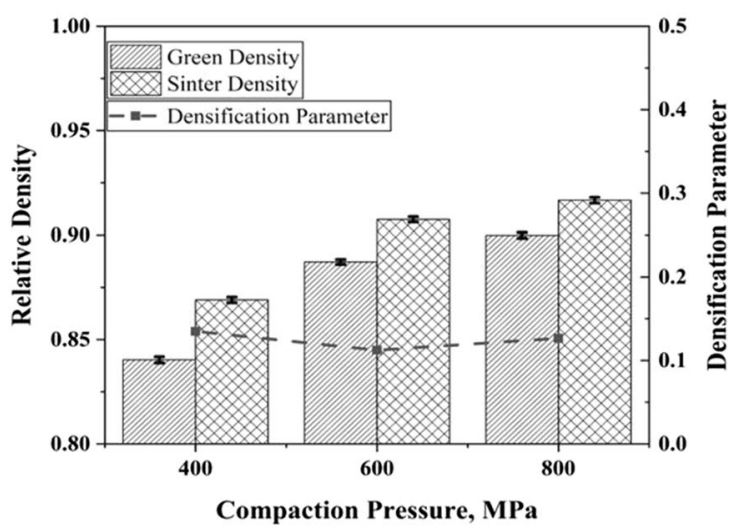

(d)

Fig. 5-Relative green and sinter densities along with the densification parameter for compacts sintered at $1350{ }^{\circ} \mathrm{C} ;(a) \mathrm{M}-5$ pct $\mathrm{Fe},(b) \mathrm{M}-5$ pct $\mathrm{Fe}+\mathrm{C},(c) \mathrm{M}-5$ pct LAS and (d) M-5 pet LAS + C.

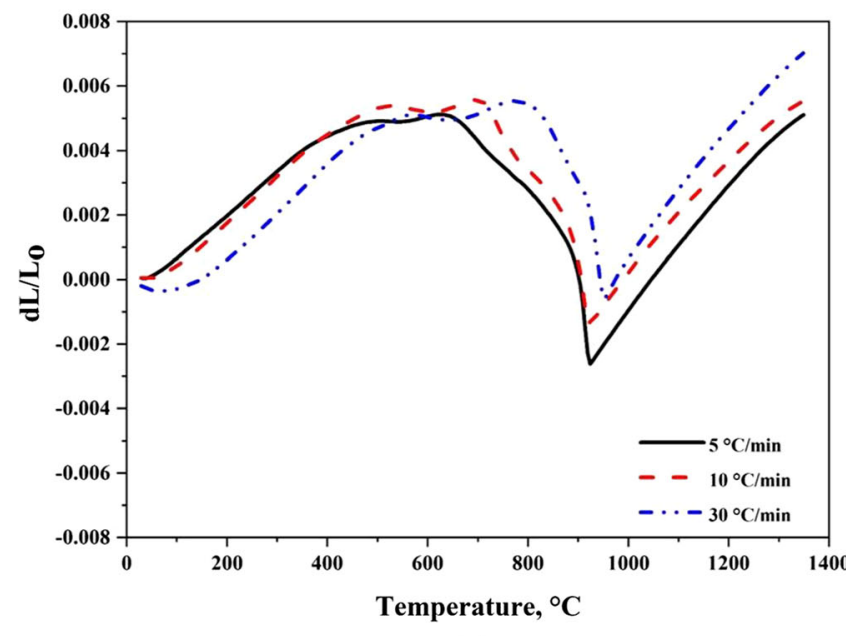

(a)

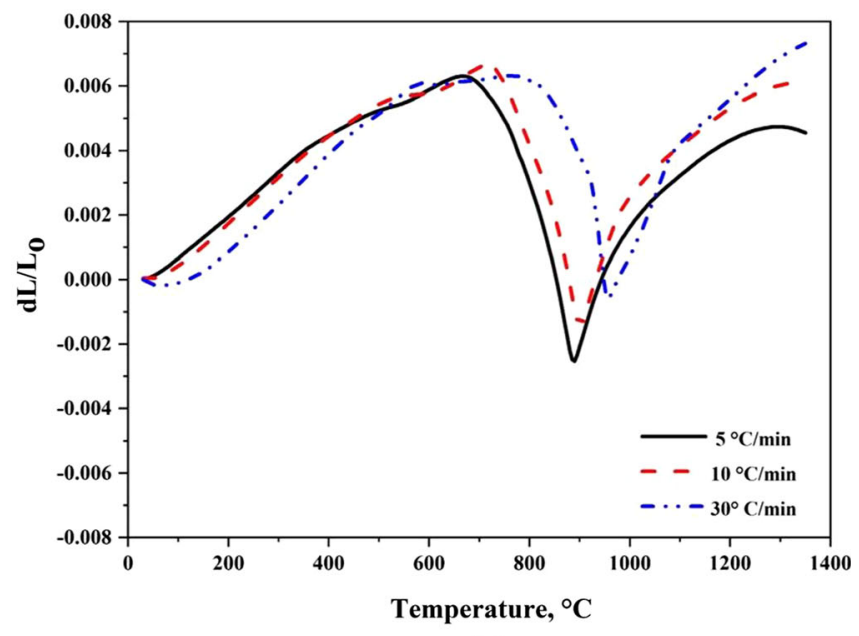

(b)

Fig. 6- Heating section of the sintering curves showing the influence of heating rate; (a) M-5 pct Fe and $(b) \mathrm{M}-5$ pct Fe + C.

temperature increased from $890{ }^{\circ} \mathrm{C}$ to $956{ }^{\circ} \mathrm{C}$ when the heating rate was changed from $5{ }^{\circ} \mathrm{C} / \mathrm{min}$ to $30^{\circ} \mathrm{C} / \mathrm{min}$ (Figure 6(b)). ${ }^{[15]}$ Compacts pressed at 400 and $800 \mathrm{MPa}$ showed similar behavior. The full sintering curve shows that the heating rate does not appear to have a substantial influence on the sinter density. 
The initial sintering experiments with two nanopowder and micropowder systems (M-Fe and M-LAS) were conducted to identify the system with the higher potential densification and to further study the mechanisms involved. The experiments found that the $\mathrm{M}-\mathrm{Fe}$ system had the higher potential densification. Therefore, we further analyzed this system. The results obtained from this analysis would then be utilized to understand the behavior of steel and associated alloy systems as sintering aid and to fine-tune them for optimal densification performance, which will be a subject of future work. The lower densification in the LAS-containing system could be attributed to the physical and chemical characteristics of the nanopowder chosen (i.e., higher agglomeration tendency and prevalent oxide in surface chemistry).

\section{Influence of Nanopowder Addition}

After establishing the behavior of the sintered powder blend compacts, the influence of the nanopowder addition on the sintering of micrometre-sized powder is described in this section. To this end, the sintering behavior of the compacts of powder blends is compared to that of micrometre-sized powder compacts. Compacts containing only micrometre-sized iron powder and pressed at similar compaction pressures were sintered using identical sintering conditions. Figure 7 shows the sinter curve of both the powder blend compact (M-5 pct $\mathrm{Fe}$ ) and micrometre-sized powder compact. Though the shapes of their sinter curves are similar, a clear deviation in their nature is apparent, as shown in the highlighted region of Figure 7(a). This region is shown at higher magnification in Figure 7(b), which depicts the behavior during part of the heating stage from approximately 500 ${ }^{\circ} \mathrm{C}$ to $900{ }^{\circ} \mathrm{C}$. The difference in the shape of the curve here is attributed to the presence of nanopowder in the sintered powder blend compact, because the remaining parameters have not been changed. To understand this difference, the powder blend compacts were sintered at

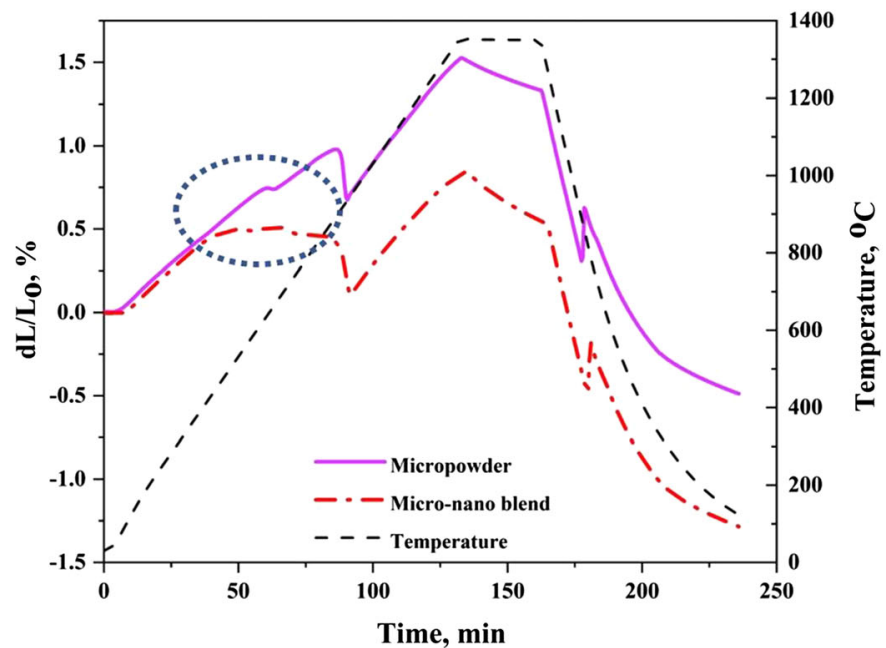

(a) intermittent temperatures of $500{ }^{\circ} \mathrm{C}, 700{ }^{\circ} \mathrm{C}, 900{ }^{\circ} \mathrm{C}$ and $1100{ }^{\circ} \mathrm{C}$.

After sintering, these compacts were subjected to fractography analysis. Figure 8 shows the morphological differences revealed on the fracture surfaces with respect to the sintering temperature. The fracture surface of the green compact revealed nanopowder between micropowder particles (Figure 8(a)). Compacts sintered at $500{ }^{\circ} \mathrm{C}$ also revealed nanopowder between micrometre-sized metal particles (Figure 8(b)). This nanopowder appeared to be devoid of any necks or bonds between particles, and the particles were discernible. Nanopowder coalescence was observed after sintering these compacts at $700{ }^{\circ} \mathrm{C}$ (Figure 8(c)). The nanoparticles began to be sintered and were then sintered onto the micrometre-sized particles. This shows that the nanopowder sintering was activated at between $500{ }^{\circ} \mathrm{C}$ and $700{ }^{\circ} \mathrm{C}$ and resulted in a single mass at 700 ${ }^{\circ} \mathrm{C}$. The sintering was conducted in pure hydrogen, which implies that the nanometric iron-oxide scales on the nanopowder and most of the micrometre-sized powder were reduced, and this aided the sintering process. ${ }^{[16]}$ Complete sintering of the nanopowder was achieved by $700{ }^{\circ} \mathrm{C}$. No nanopowder was observed after heating to $900{ }^{\circ} \mathrm{C}$, although the neck morphology remained apparent (Figure 8(d)). The single mass found in Figure 8(c) was found to coarsen at $900{ }^{\circ} \mathrm{C}$. Nanoparticles could not be distinguished after heating to $1100{ }^{\circ} \mathrm{C}$ (Figure $8(\mathrm{e})$ ). In addition to the iron-oxide layer, with a thickness of approximately $7 \mathrm{~nm}$, the micron-sized powder used in this study was to a small extent $(<5$ pct) dotted with oxide particulate features sized up to $100 \mathrm{~nm}$ and rich in strong oxide formers such as $\mathrm{Cr}$ and $\mathrm{Mn} \cdot{ }^{[17]}$ These oxide particulates were reduced above $1100{ }^{\circ} \mathrm{C}$ when sintered in pure hydrogen. The fracture surface of the compact sintered at $1350{ }^{\circ} \mathrm{C}$ revealed dimples, which were this devoid of any oxide particles. This was because sintering in the pure hydrogen atmosphere helps reduce nearly all oxides in the system, internal oxides or features on the surface of the

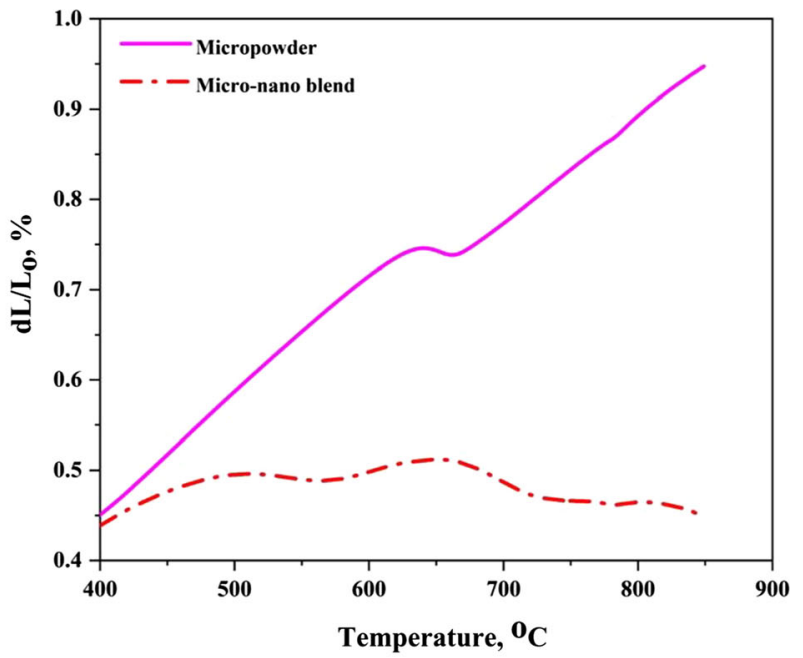

(b)

Fig. 7-(a) Sinter curves of powder blend compact and micrometre-sized compact sintered at $1350{ }^{\circ} \mathrm{C}$; (b) higher magnification of 7 a showing the difference in sintering behavior due to the presence of nanopowder in the compact. 

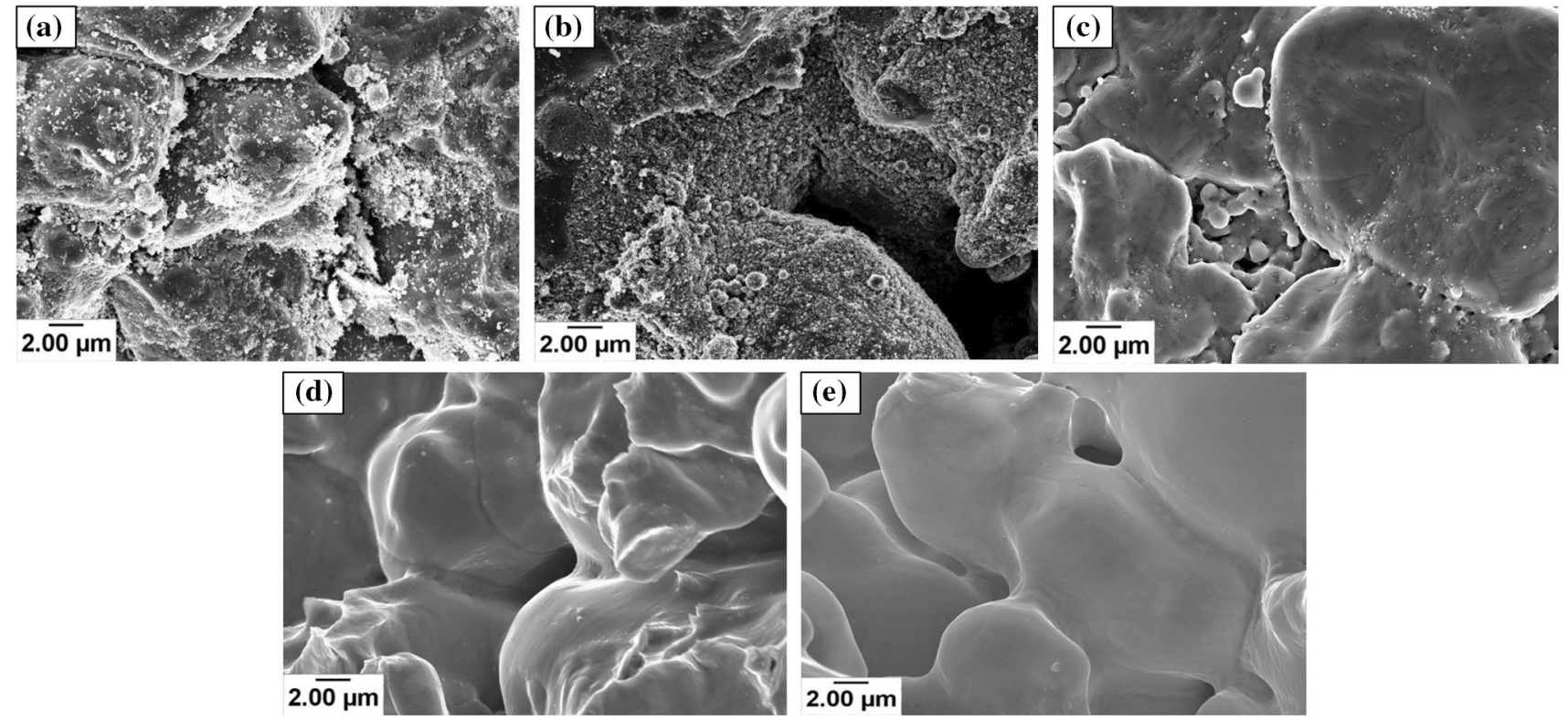

Fig. 8 - Scanning electron micrographs showing the evolution of the microstructure various M-5 pct Fe compacts at different temperatures; (a) green compact, (b) sintered at $500{ }^{\circ} \mathrm{C},(c)$ sintered at $700{ }^{\circ} \mathrm{C},(d)$ sintered at $900{ }^{\circ} \mathrm{C}$ and $(e)$ sintered at $1100{ }^{\circ} \mathrm{C}$.
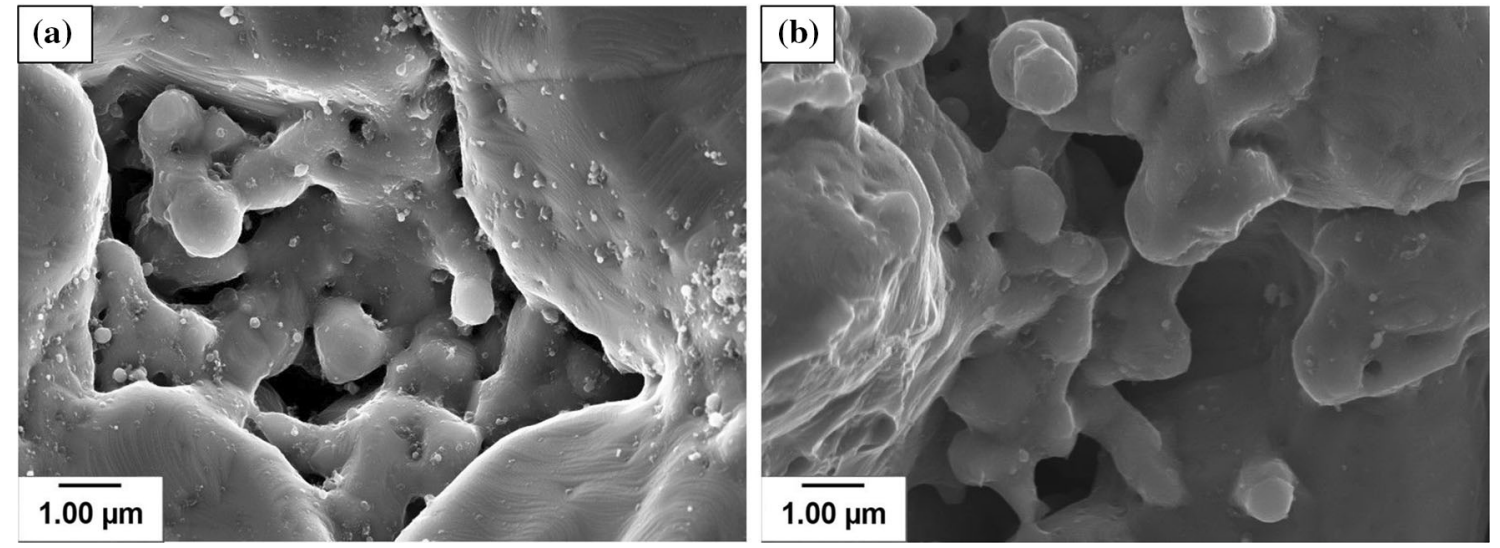

Fig. 9-(a) and (b) Scanning electron microscope fractographs of a powder blend compact, M-5 pct Fe, sintered at $700{ }^{\circ} \mathrm{C}$.

powder, even if carbon is not added. This reduction of oxides was due to the high temperature applied for the pure hydrogen atmosphere. ${ }^{[17]}$

The role played by nanopowder in the sintering process was thus mainly observed at temperatures between $500{ }^{\circ} \mathrm{C}$ and $700{ }^{\circ} \mathrm{C}$. Nanopowder present in the inter-particle spaces and at the boundaries appeared to be sintered. It was also sintered onto the micrometre-sized powder (Figures 9(a) and (b)). This can be described as a two-stage process. In the first stage, nanopowder sinters itself, due to the reduction of its surface iron-oxide layer and enhanced surface energy. In the second stage, it pulls the micrometre-size powder together and increases the contact surface between them by sintering to the micropowder. A similar phenomenon was observed by Lee et al. ${ }^{[8]}$ in the sintering of material molded by MIM. They observed that nanopowder sintering at the boundaries and corners contribute to the enhancement of the densification process in a micro-nanopowder system by increasing contact probability and diffusion paths. Figure 9 shows that there was porosity outside of the single-mass structure. It is possible that this porosity was inter-agglomerate porosity and that the single-mass structure was an agglomerate of nanopowder which transformed upon heating into a single particle-like structure. The gap between the agglomerates thus formed the inter-agglomerate porosity.

As shown in the fractographs (Figure 8), nanopowder was sintered in the temperature range between $500{ }^{\circ} \mathrm{C}$ and $700{ }^{\circ} \mathrm{C}$. As the sintering was conducted in a pure hydrogen atmosphere, which reduces iron oxide in the range of temperatures between $300{ }^{\circ} \mathrm{C}$ and $500{ }^{\circ} \mathrm{C},{ }^{[9]}$ the oxide scale covering the nanoparticles was reduced. The oxide layer plays a crucial part in sintering, as sintering is a surface phenomenon. The change in the sintering curve between the powder blend compact and the micrometre-sized powder compact could be attributed 
to the various changes undergone by the nanopowder. In nanopowder sintering, necking is possible at temperatures as low as $350{ }^{\circ} \mathrm{C}$ if the surface is reduced, though it might not result in densification because the dominant mechanism is surface diffusion $\left(D_{\mathrm{s}}\right){ }^{[2]}$ Densification is observed when a combination of surface diffusion and grain-boundary diffusion is likely to be the dominant mechanism. Within the nanopowder agglomerates, this occurs at low temperature because the critical neck size is reached between the particles. Neck growth beyond this critical size requires an increase in particle size. ${ }^{[18]}$ Therefore, larger particles grow at the expense of smaller particles. This process is known as the ripening process, and the rate at which it occurs is based on the particle size. In other words, the rate is high when the particle is small because the total surface area of these fine particles is large. When this phenomenon occurs, the chain length of the particles decreases within the agglomerate, and shrinkage occurs. ${ }^{[19]}$ In the present case, sintering of the nanopowder occurred between 500 ${ }^{\circ} \mathrm{C}$ and $700{ }^{\circ} \mathrm{C}$. Intra-agglomerate sintering appeared to occur producing inter-agglomerate pores.

\section{Densification Kinetics}

An attempt was made to calculate the densification kinetics using two approaches. Compacts pressed at 600 $\mathrm{MPa}$ were chosen for this theoretical analysis. In both approaches, shrinkage obtained at different heating rates was used. Densification kinetics was measured under non-isothermal conditions. Sintering kinetics under non-isothermal conditions is more correct than under isothermal conditions. ${ }^{[20]}$ Densification also occurs during the initial stages of the heating process, and therefore, it is difficult to determine whether changes occur during heating or isothermal holding. ${ }^{[21]}$ To investigate the densification kinetics and the dominant mechanism, the non-isothermal sintering was thus analyzed.

The apparent activation energy, $Q$, is used to describe the amount of energy that must be overcome to begin a densification reaction by a diffusion process during sintering. It was evaluated using two approaches. In the first approach, the temperature required to obtain identical shrinkage values at different heating rates was used. For the second approach, the shrinkage rate itself was used. The peak temperature for different heating rates was considered. Both approaches used an Arrhenius-type equation as a basis for calculating the apparent activation energy.

In the first approach, $Q$ is extracted by plotting the ratio of heating rates $\Phi_{i}$ and temperature $T_{i}$ required for identical shrinkage values against the reciprocal temperature, $1 / T_{i}$. The required equation is the following:

$$
\ln \left(\frac{\Phi_{i}}{T_{i}^{2}}\right)=\ln \left(\frac{C R}{Y^{n} Q}\right)-\frac{Q}{R T_{i}},
$$

where $Y$ is the shrinkage denoted as $Y=\frac{\Delta L}{L_{0}}, C$ is the pre-exponential constant and $R$ is the universal gas constant. Identical shrinkage values were considered, and the corresponding temperatures at different heating

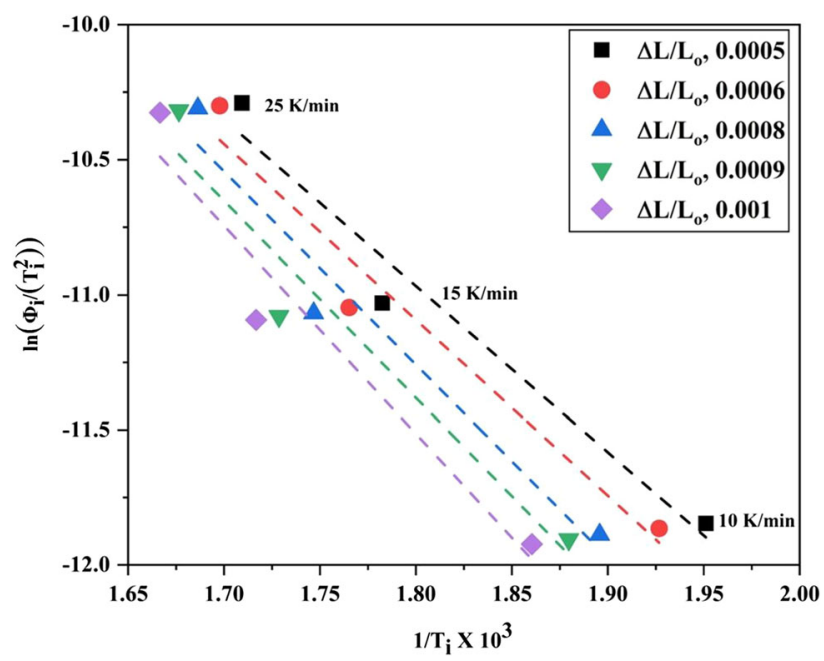

Fig. 10-Plot of $\ln \left(\frac{\Phi_{i}}{T_{i}^{2}}\right)$ vs $\frac{1}{T_{i}}$ obtained from shrinkage data using Eq. [2].

Table II. Activation Energy Values Using Shrinkage Data

\begin{tabular}{lccc}
\hline$\Delta L / L_{\mathrm{o}}$ & Slope & $R^{2}(\mathrm{Pct})$ & Activation Energy $(\mathrm{kJ} / \mathrm{mol})$ \\
\hline 0.0005 & $-6.15 \pm 1.22$ & 96.2 & $50 \pm 9$ \\
0.0006 & $-6.50 \pm 1.36$ & 95.7 & $53 \pm 11$ \\
0.0008 & $-7.15 \pm 1.57$ & 95.3 & $58 \pm 12$ \\
0.0009 & $-7.29 \pm 1.86$ & 93.8 & $60 \pm 15$ \\
0.001 & $-7.69 \pm 1.96$ & 93.9 & $63 \pm 16$ \\
\hline
\end{tabular}

rates were taken. Sintering was conducted at three different heating rates, giving three sets of data points. Values of $\ln \left(\frac{\Phi_{i}}{T_{i}^{2}}\right)$ vs $\frac{1}{T_{i}}$ were plotted, and least-squares fitting was applied (Figure 10). The slope obtained was multiplied by $-R$ to obtain the apparent activation energy values. Details on the curve fitting are given in Table II. In this way, $Q$ was calculated for the shrinkage values in the temperature range of $450{ }^{\circ} \mathrm{C}$ to $700{ }^{\circ} \mathrm{C}$. The fractographs show that the sintering of nanopowder occurred in the temperature range between $500{ }^{\circ} \mathrm{C}$ and $700{ }^{\circ} \mathrm{C}$ (Figure 8). Consequently, the shrinkage values in this range were considered for the calculation of $Q$. The results show that the activation energy for the densification varied within the range of 45 to $70 \mathrm{~kJ} / \mathrm{mol}$ (Table II).

The sintering mechanism for solid-state sintering is mainly dependent on diffusion-controlled processes: surface, grain-boundary and volume diffusion. ${ }^{[22]}$ The activation energy value for densification increases with an increasing sinter density. The values obtained appear to be in agreement with the activation energy of the grain-boundary self-diffusion of pure iron, which is in the range of 53 to $80 \mathrm{~kJ} / \mathrm{mol}^{[23]}$ Song et al. ${ }^{[20]}$ also observed similar activation energy values while studying the sintering behavior of bimodal iron nanopowder agglomerates.

For the second approach, the rate of shrinkage for different heating rates was considered, and the Kissinger equation was used. ${ }^{[24]}$ With the Arrhenius equation as 
Table III. Activation Energy Values from Approach Using Shrinkage Rate

\begin{tabular}{lccr}
\hline Sintered Compacts & Slope & $R^{2}(\mathrm{Pct})$ & Activation Energy $(\mathrm{kJ} / \mathrm{mol})$ \\
\hline M-5 Pct Fe & $-29.694 \pm 4.16$ & 94.41 & $246 \pm 34$ \\
\hline
\end{tabular}

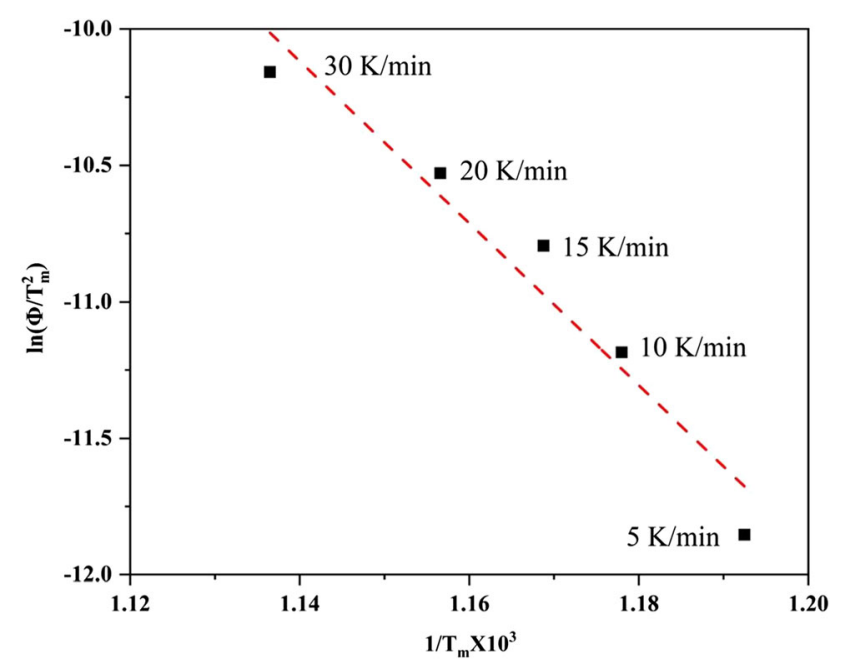

Fig. 11-Plot of $\ln \frac{\Phi}{T_{\mathrm{m}}^{2}}$ vs $\frac{1}{T_{\mathrm{m}}}$ obtained from the shrinkage rate data using Eq. [3].

its foundation, this equation can be applied to calculate the activation energy. This equation is widely used for the study of structural transformations. The slope of the Kissinger plot $\left(\ln \frac{\Phi}{T_{\mathrm{m}}^{2}} v s \frac{1}{R T_{\mathrm{m}}}\right)$ is the activation energy. The Kissinger equation is given by

$$
\ln \frac{\Phi}{T_{m}^{2}}=-\frac{1}{T_{m}} \frac{E_{a}}{R},
$$

where $\Phi$ is the heating rate $(\mathrm{K} / \mathrm{min}), T_{\mathrm{m}}$ is the peak temperature $(\mathrm{K}), E_{\mathrm{a}}$ is the activation energy $(\mathrm{kJ} / \mathrm{mol})$ and $R$ is the universal gas constant $(\mathrm{kJ} /[\mathrm{K}$ mol] $)$.

The apparent activation energies using the above approach were calculated for the M-5 pct Fe sintered compacts pressed at $600 \mathrm{MPa}$, and the peak value was taken from the rate of sintering at between $500{ }^{\circ} \mathrm{C}$ and $700{ }^{\circ} \mathrm{C}$. The calculations yielded an activation energy value of $246 \mathrm{~kJ} / \mathrm{mol}$ (Table III; Figure 11). These values are higher than the values obtained by previous researchers of 53 to $80 \mathrm{~kJ} / \mathrm{mol}$ for grain-boundary diffusion in iron. ${ }^{[23]}$ One of the widely accepted mechanisms of sintering is that at low temperatures, surface diffusion dominates, but there is no shrinkage involved. This then shifts to grain-boundary and volume diffusion as the temperature is increased. The grain-boundary area in nanopowder is much higher because the boundary is formed between the neighboring metal particles. There was no apparent presence of necks between the particles at $500{ }^{\circ} \mathrm{C}$, but the powder was sintered at 700 ${ }^{\circ} \mathrm{C}$. Therefore, the mechanism must be active in this temperature range for the nanopowder, which contradicts the calculated activation energy values, as they do

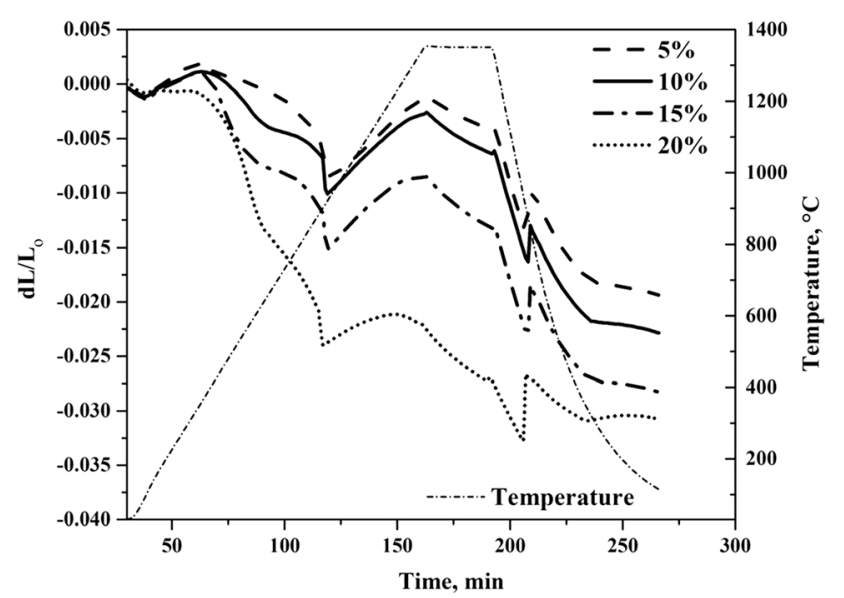

Fig. 12-Sintering curves of compacts containing 5, 10, 15 and $20 \mathrm{wt}$ pet nanopowder sintered at $1350^{\circ} \mathrm{C}$.

not match the literature value for grain-boundary diffusion. Thus, this approach might not be suitable to calculating the activation energy in sinter compacts containing nanopowder.

\section{E. Varying the Amount of Nanopowder}

Figure 12 shows the effect on sinter curves as the nanopowder content is increased in the compact. The linear shrinkage increased from 1.5 to 3.0 pct when the nanopowder content was increased from 5 to $20 \mathrm{wt}$ pct. Assuming that a uniform volumetric shrinkage would be achieved, an approximate volumetric shrinkage of 3 times the linear shrinkage, corresponding to 9 pct, can be expected with 20 wt pct nanopowder. Considering an initial density of 90 pct, a shrinkage corresponding to 95 pct density is necessary for achieving closed porosity in the compacts. Having 9 pct volumetric shrinkage would then enable subsequent hot isostatic pressing without the need for a capsule. This hot isostatic pressing would allow theoretical density to be achieved. The slope of the dilatometer curve was steeper for the compact with 20 wt pet nanopowder than for the compacts with 5, 10 and $15 \mathrm{wt}$ pct. The extent of densification was also higher in the case of the $20 \mathrm{wt}$ pct nanopowder compact. Activation due to the addition of nanopowder was thus achieved, and the extent of activation is influenced by the amount of nanopowder in the compact. As the nanopowder content was increased in the powder blend, the green density was reduced. With decreasing green density, the densification parameter increased because the compact underwent higher densification with sintering. 
Figure 13 shows the density of compacts sintered at $1350{ }^{\circ} \mathrm{C}$. A marginal increase in the density was observed with increasing nanopowder content. To understand the impact of nanopowder addition on the density, the densification parameter was used. ${ }^{[12]}$ An increase in the parameter value was observed, which means that the extent of densification increased with increasing nanopowder content. From a value of 0.14

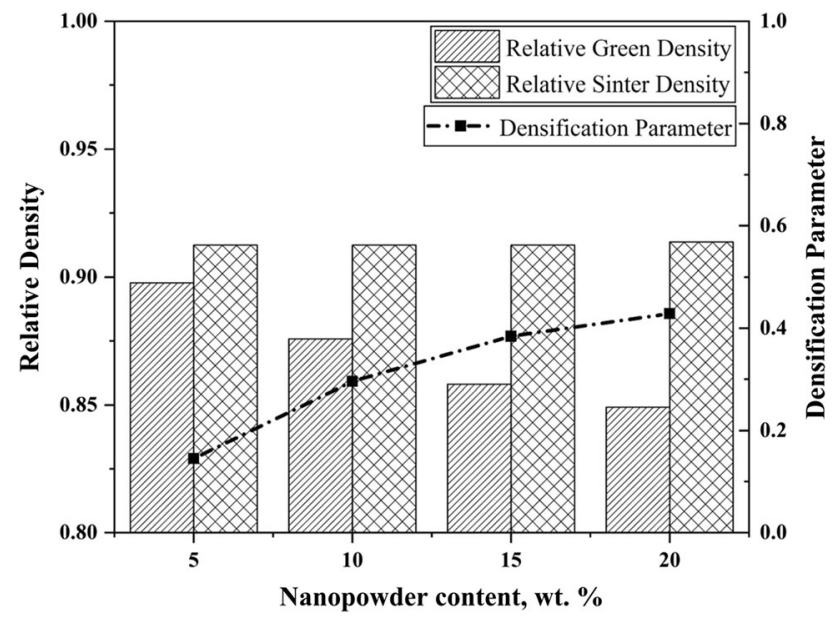

Fig. 13 - Plot showing the effect of nanopowder on the sinter density of the compact and the increase in densification with an increase in nanopowder content using the densification parameter. for the compact with $5 \mathrm{wt}$ pct nanopowder, it increased to approximately 0.45 for the compact with $20 \mathrm{wt}$ pet nanopowder.

Figures 14(a) through (d) each show a cross-section of compacts with 5 or $15 \mathrm{wt}$ pct iron nanopowder sintered at $500{ }^{\circ} \mathrm{C}$. As it has been established that the nanopowder retained its particle size at $500{ }^{\circ} \mathrm{C}$ (Figure 8), the cross-section micrographs reveal the presence of nanopowder between the micrometre-sized particles. The presence of such agglomerates is significant in the case of the compact with 15 wt pct iron nanopowder compared to the compact with 5 wt pct iron nanopowder. Upon increasing the temperature of the sintering to $700{ }^{\circ} \mathrm{C}$, the morphology of these 'pockets' changed, because the nanopowder was no longer at the nanoscale.

\section{CONCLUSIONS}

The present study has illustrated the sintering behavior of water-atomized iron powder in the presence of nanopowder. It has shown that the presence of nanopowder decreases the compressibility of powder. The rigidity of nanopowder and the loss in compaction force are due to increased internal friction. These properties reduce the green density of the compacts containing nanopowder. The sinter curve was found to vary due to the presence of nanopowder, implying that the nanopowder influences the sintering behavior. The compaction and sinter density of the compacts varied
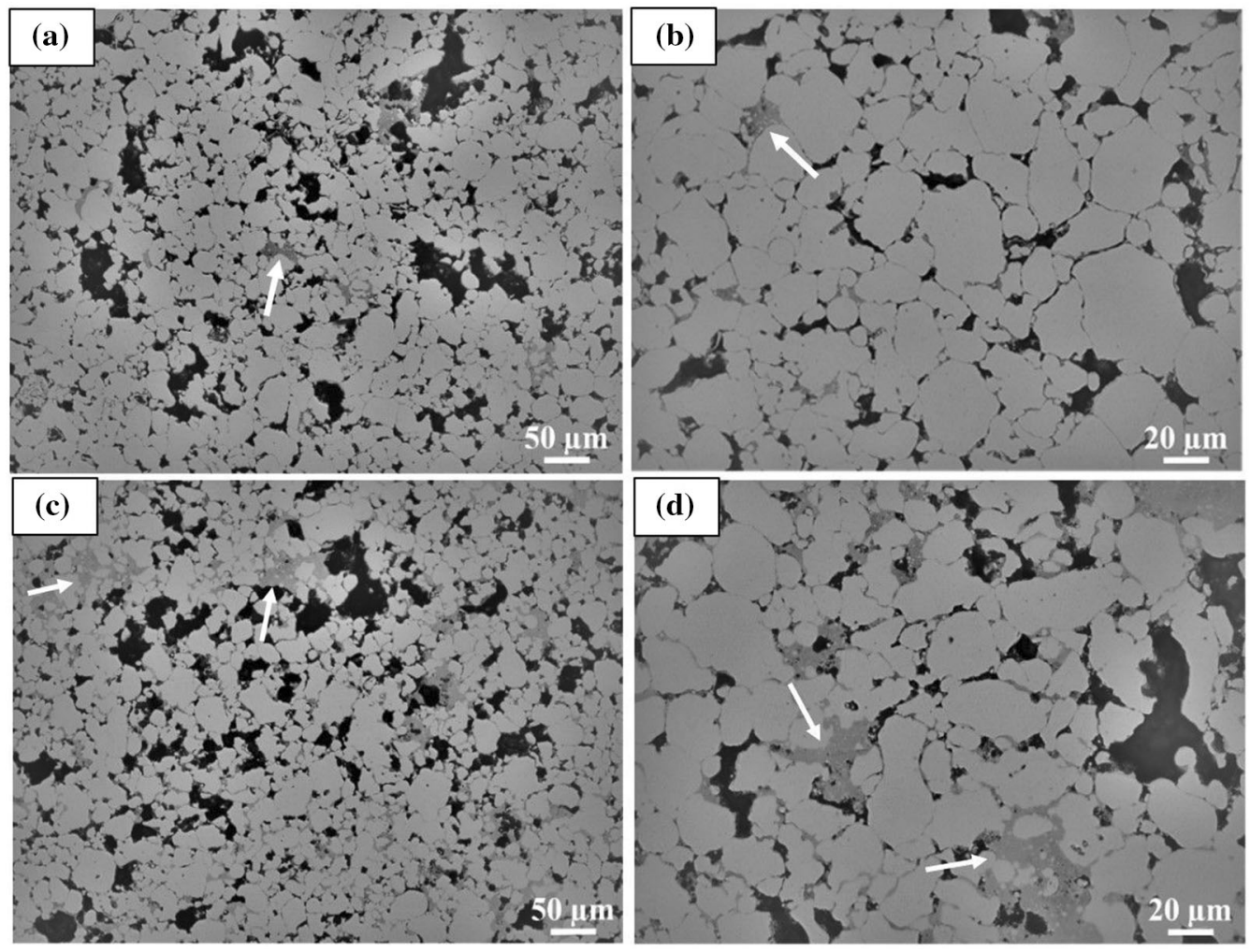

Fig. 14 Optical micrographs showing the presence of nanopowder between the micropowder particles (shown by the arrows) for (a) and (b) compact with 5 pet iron nanopowder sintered at $500{ }^{\circ} \mathrm{C}$ and $(c)$ and $(d)$ compact with 15 pct iron nanopowder sintered at $500{ }^{\circ} \mathrm{C}$. 
according to the compaction pressure and the composition of the compacts. With respect to the difference in the behavior of the sinter curves, the compact with nanopowder showed shrinkage at temperatures as low as $500{ }^{\circ} \mathrm{C}$ compared to the compact containing only micrometre-sized iron powder. The fractographic analysis on the compacts which underwent sintering at intermittent temperatures also revealed that the nanopowder in the compact was sintered at temperatures between $500{ }^{\circ} \mathrm{C}$ and $700{ }^{\circ} \mathrm{C}$. An attempt was made to understand the densification kinetics involved in sintering using two approaches: shrinkage data and shrinkage rate data. The first approach was found to be more appropriate, and it yielded expected $Q$ values for grain-boundary diffusion. As a result, grain-boundary diffusion dominates the kinetics of the material transport involving the effect of nanopowder during the heating stage. Linear shrinkage measured from the dilatometry results showed an increase from 1.5 to 3.0 pct when the nanopowder content was increased from 5 to $20 \mathrm{wt}$ pct in the compacts. Hence, nanopowder addition opens a path for the sintering of powder compacts to closed porosity. The nature of the sinter curve changed beyond $500{ }^{\circ} \mathrm{C}$ in accordance with the content of nanopowder present in the compact.

\section{ACKNOWLEDGMENTS}

Open access funding provided by Chalmers University of Technology. The authors would like to acknowledge the Swedish Foundation for Strategic Research for the research grant. The authors would also like to acknowledge Höganäs $\mathrm{AB}$ for the supply of powder and compaction experiments.

\section{OPEN ACCESS}

This article is licensed under a Creative Commons Attribution 4.0 International License, which permits use, sharing, adaptation, distribution and reproduction in any medium or format, as long as you give appropriate credit to the original author(s) and the source, provide a link to the Creative Commons licence, and indicate if changes were made. The images or other third party material in this article are included in the article's Creative Commons licence, unless indicated otherwise in a credit line to the material. If material is not included in the article's Creative Commons licence and your intended use is not permitted by statutory regulation or exceeds the permitted use, you will need to obtain permission directly from the copyright holder. To view a copy of this licence, visit http://creat ivecommons.org/licenses/by/4.0/.

\section{REFERENCES}

1. H. Djohari and J.J. Derby: Chem. Eng. Sci., 2009, vol. 64, pp. $3810-16$.

2. R.M. German: in Sintering: From Empirical Observations to Scientific Principles, R.M. German, ed., Butterworth-Heinemann, Boston, 2014, pp. 141-81.

3. F. Wakai, M. Yoshida, Y. Shinoda, and T. Akatsu: Acta Mater., 2005, vol. 53, pp. 1361-71.

4. J. Rajabi, N. Muhamad, and A.B. Sulong: Microsyst. Technol., 2012, vol. 18, pp. 1941-61.

5. J.W. Oh, R. Bollina, W.S. Lee, and S.J. Park: Powder Technol., 2016, vol. 302, pp. 168-76.

6. D. Wei, R. Dave, and R. Pfeffer: J. Nanoparticle Res., 2002, vol. 4, pp. 21-41.

7. J. Fruhstorfer, S. Schafföner, and C.G. Aneziris: Ceram. Int., 2014, vol. 40, pp. 15293-15302.

8. J.-P. Choi, H.-G. Lyu, W.-S. Lee, and J.-S. Lee: Powder Technol., 2014, vol. 253, pp. 596-601.

9. S.K. Manchili, R. Shvab, A. Zehri, L. Ye, E. Hryha, J. Liu, and L. Nyborg: Surf. Interface Anal., 2018, vol. 50, pp. 1083-88.

10. O. Dominguez, M. Phillippot, and J. Bigot: Scripta Metall. Mater., 1995, vol. 32, pp. 13-17.

11. S.V. Matrenin, A.P. Il, A.I. Slosman, and L.O. Tolbanova: Russ. J. Non-Ferrous Met., 2009, vol. 50, pp. 513-17.

12. S. Patra, A. Gouthama, and K. Mondal: Prog. Nat. Sci. Mater. Int., 2014, vol. 24, pp. 608-22.

13. Manufacturing processes laboratory (mse 315), https://www.iitk. ac.in/mse/data/MSE_315A.pdf, (accessed 1 October 2018).

14. J. Langner and J.R. Cahoon: Metall. Mater. Trans. A, 2010, vol. 41A, pp. 1276-83.

15. E. Hryha, L. Nyborg, and L. Alzati: Powder Metall., 2015, vol. 58, pp. $7-11$

16. D. Sivaprahasam, A.M. Sriramamurthy, S. Bysakh, G. Sundararajan, and K. Chattopadhyay: Metall. Mater. Trans. A, 2018, vol. 49A, pp. 1410-24.

17. J. Wendel, R. Shvab, Y. Cao, E. Hryha, and L. Nyborg: Surf. Interface Anal., 2018, vol. 50, pp. 1065-71.

18. Z.Z. Fang and H. Wang: Int. Mater. Rev., 2008, vol. 53, pp. 326-52.

19. D. Sivaprahasam, A.M. Sriramamurthy, S. Bysakh, and G. Sundararajan: Metall. Mater. Trans. A, 2018, vol. 49A, pp. $1410-24$.

20. J. Song, G.-Y. Lee, E.-J. Hong, C.S. Lee, and J.-S. Lee: J. Am. Ceram. Soc., 2019, vol. 102, pp. 3791-3801.

21. M.V. Gropyanov and G.V. Abbakumov: Sci. Sinter., 1975, vol. 7, pp. 3-15.

22. R.M. German: Sintering Theory and Practice, Wiley, New York, 1996.

23. A. Inoue, H. Nitta, and Y. Iijima: Acta Mater., 2007, vol. 55, pp. $5910-16$.

24. P. Roura and J. Farjas: J. Mater. Res., 2009, vol. 24, pp. 3095-98.

Publisher's Note Springer Nature remains neutral with regard to jurisdictional claims in published maps and institutional affiliations. 